\title{
JOGOS DIGITAIS DE ALFABETIZAÇÃO: UM PANORAMA PEDAGÓGICO DE ALGUMAS PRODUÇÕES ACADÊMICAS BRASILEIRAS
}

\section{DIGITAL LITERACY GAMES: A PEDAGOGICAL OVERVIEW OF SOME BRAZILIAN ACADEMIC PRODUCTIONS}

\author{
Chris Royes Schardosim* \\ Thiago Ribeiro Alves**
}

\begin{abstract}
Resumo: Este artigo realiza, a partir do recorte da pesquisa de mestrado, um levantamento de algumas produções acadêmicas brasileiras que abordam a temática dos jogos digitais de alfabetização, buscando problematizar as teorias de aprendizagem aplicadas ou não na sua elaboração. Os jogos analisados neste artigo demonstram a necessidade de uma intervenção interdisciplinar (FAZENDA, 2008) na produção, no desenvolvimento e na aplicação desse tipo de ferramenta, em especial no campo da alfabetização. Em alguns casos, as produções acadêmicas analisadas, embora apresentem avanços significativos, ainda carecem de maior debate, problematização e embasamento sobre as teorias pedagógicas e os processos educativos envolvidos nos jogos digitais de alfabetização.
\end{abstract}

Palavras-chave: Alfabetização. Jogos digitais. Processos educativos. Recursos tecnológicos na aprendizagem.

Abstract: This article conducts, based on the Master's research, a survey of some Brazilian academic productions that address the theme of digital literacy games seeking to problematize the learning theories applied or not in the elaboration of these games. The games analyzed in this article demonstrate the need for an interdisciplinary intervention (FAZENDA, 2008) in the production, development and application of this type of tool, especially in the field of literacy. In some cases, the academic productions analyzed, although presenting significant advances, still lack further debate, problematization and grounding on the pedagogical theories and educational processes involved in digital literacy games.

Keywords: Literacy. Digital games. Educational processes. Technological resources in learning.

\section{Introdução}

A alfabetização deixou de ser um tema exclusivo das escolas há um bom tempo, felizmente. Atualmente há diversas áreas interessadas pelo tópico. Porém, antes de iniciar a discussão central deste texto - os jogos digitais de alfabetização, faremos uma ressalva importante sobre o termo alfabetização. Em artigo publicado recentemente, Royes Schardosim e Alves (2019) discutem os termos alfabetização,

\footnotetext{
* Professora de Ensino Básico, Técnico e Tecnológico (EBTT) no Instituto Federal Catarinense (IFC) no Campus Ibirama desde 2013. Atua no Ensino Médio com a disciplina língua espanhola, na Especialização em Educação com as disciplinas Metodologia de pesquisa e Leitura e produção do texto acadêmico. A partir de 2019 atua 20 horas no IFC Campus Camboriú no Mestrado Acadêmico em Educação, também com Metodologia e Leitura. Doutora em Linguística (2015) pela Universidade Federal de Santa Catarina (UFSC) com bolsa de estágio de doutorado no exterior pela Deutscher Akademischer Austauschdienst (DAAD) na Universität Augsburg, na Alemanha, Mestre em Linguística (2010) e Licenciada em Letras Espanhol (2008) também pela UFSC. Possui experiência na área de Linguística, atuando principalmente nos seguintes temas: compreensão leitora, estratégias de leitura e ensino-aprendizagem de português como língua materna e espanhol como língua estrangeira, nas modalidades presencial e a distância. Email: chris.schardosim@ifc.edu.br

** Graduado em Geografia pela Universidade do Estado de Santa Catarina (UDESC). Mestrando no Programa de Pós-Graduação em Educação, no curso de Mestrado Acadêmico em Educação do Instituto Federal Catarinense (IFC) Campus Camboriú. Professor auxiliar em Tecnologia Educacional na Prefeitura de Florianópolis. E-mail: thiagoalves.pmf@ gmail.com
} 
letramento e literacia - que inclusive têm a mesma tradução em inglês: literacy. Por isso, a partir da concepção desses autores, neste texto utilizamos o termo alfabetização entendendo que "[...] a alfabetização é, no processo de ensino da leitura e escrita, a apropriação dos códigos do alfabeto, da memorização/compreensão da relação entre os grafemas e seus respectivos fonemas - e vice-versa" (ROYES SCHARDOSIM; ALVES, 2019, p. 82).

Após essa breve contextualização, voltamos ao tema, que não é mais objeto de estudo e análise apenas das escolas e dos professores/pesquisadores de português, até porque ensinar a ler é compromisso de todas as áreas (GUEDES; SOUZA, 2011). Além de estudiosos da educação, diversos outros campos do saber têm contribuído para a compreensão dos processos envolvidos no ensino e aprendizado da leitura e da escrita, como a linguística, a psicologia, a neurologia, a neurolinguística, a medicina, a fonoaudiologia, entre outras. Mais recentemente, áreas relacionadas às ciências da computação também colocaram o tema em suas pautas. Em especial, a produção de jogos digitais educacionais tem se mostrado um espaço promissor ao encontro dessas áreas. Sem dúvida, essa interdisciplinaridade (FAZENDA, 2008) é bastante salutar - e essencial - para o desenvolvimento eficiente da alfabetização como campo de estudo. Contudo, a junção desses saberes em um produto educacional é ainda um desafio, e não necessariamente essas diferentes áreas têm conversado de maneira adequada. Nesse aspecto, Magda Soares, já em 1982, no livro Alfabetização no Brasil: o estado do conhecimento, mostrava preocupação quanto à necessidade de uma articulação eficiente entre diferentes áreas interessadas em contribuir com as discussões acerca da alfabetização. Fortalecendo o contexto aqui apresentado, a autora afirma que:

[...] a multiplicidade de perspectivas e pluralidades de enfoques sobre alfabetização não trarão colaboração realmente efetiva enquanto não se tentar uma articulação das análises provenientes de outras áreas de conhecimento, articulação que busque ou integrar estruturalmente estudos e resultados de pesquisas, ou evidenciar e explicar incoerências e resultados incompatíveis. Um primeiro e indispensável passo nesse sentido é a revisão dessas perspectivas, análises e estudos, de modo que se possa ter uma visão de "estado de conhecimento" em nosso país, na área da alfabetização: uma revisão crítica dos estudos e pesquisas sobre alfabetização que se vêm multiplicando nas últimas décadas [...]. (SOARES, 1982, p. 2).

De lá pra cá, avançamos timidamente nessa articulação de saberes, talvez pelo conveniente e positivo fato de mais áreas do saber entrarem na discussão, participando propositivamente na compreensão da temática e consequentemente reconfigurando, promovendo ajustes na conjunção de saberes. Esse sadio contexto mantém a relevância da alfabetização como campo de investigação científica, ao mesmo tempo em que mantém aceso o sinal de alerta para uma convergência coerente e harmoniosa de conhecimentos:

As práticas interdisciplinares têm estado cada vez mais presentes nas discussões sobre a educação atual [...]. A interdisciplinaridade é um modo de ensinar e aprender os conteúdos de forma mais significativa, palpável e aplicada ao cotidiano dos educandos. (ROYES SCHARDOSIM; FUSINATO, 2017, p. 99).

No entanto, não é pretensão deste texto esmiuçar o atual estado do conhecimento/ estado da arte/estado da questão/revisão de literatura (conforme a 
perspectiva teórica elencada) das pesquisas em alfabetização no Brasil, até porque tal empreitada, devido ao grande número de produções acadêmicas que contemplam a temática, exigiria mais do que um artigo permite. O que pretendemos é, através de uma perspectiva dos processos educativos, exemplificar como diferentes segmentos têm apresentado suas concepções de alfabetização, a partir do recorte realizado na pesquisa em desenvolvimento do mestrado acadêmico no Programa de Pós-Graduação stricto sensu em Educação do Instituto Federal Catarinense (IFC) campus Camboriú, em Santa Catarina. A pesquisa de mestrado, iniciada em 2019 na linha de pesquisa Processos educativos e inclusão, tem como tema os processos educativos da alfabetização e seu objeto de estudo é definido como os jogos digitais de alfabetização.

Este artigo apresenta, portanto, uma metodologia de Estado da Questão (NÓBREGA-THERRIEN; THERRIEN, 2004; NÓBREGA-THERRIEN; MENEZES; LUZ, 2018). Por se tratar de uma análise na etapa inicial da pesquisa, seria pretensioso afirmar ser este um estado da arte, ou ainda um estado do conhecimento, antes disso, este estudo configura-se como um Estado da Questão (EQ) porque “[...] não é apenas o resultado do movimento da lógica, mas considera a intuição, a reflexão e até mesmo a imaginação como fontes de inspiração" (NÓBREGA-THERRIEN; THERRIEN, 2004, p. 7). Como também esclarecem Nóbrega-Therrien, Menezes e Luz (2018, p. 138), o EQ é " [...] um estilo do qual o pesquisador pode se utilizar para gerir o processo de elaboração de sua investigação, assim como uma ferramenta essencial no que concerne ao seu percurso de produção". É bastante interessante essa metodologia do EQ, pois é "[...] norteado por um estudo criterioso que excede o levantamento bibliográfico" (NÓBREGA-THERRIEN, MENEZES, LUZ, 2018, p. 138).

Nesse sentido, apoiando-se na concepção de um Estado da Questão que demonstre "[...] o esclarecimento da posição do pesquisador e de seu objeto de estudo na elaboração de um texto narrativo, a concepção de ciência e a sua contribuição epistêmica no campo do conhecimento" (NÓBREGA-THERRIEN; THERRIEN, 2004, p. 9), este artigo exibe um levantamento inicial das produções acadêmicas pertinentes ao assunto, num recorte temporal recente - publicadas nos últimos 13 anos, já que a referência mais antiga é de 2007 - e vinculadas a instituições de ensino superior brasileiras. Destacamos que a seleção dos estudos aqui analisados foi em boa parte manual, com a perspectiva de "[...] análise-crítica do material levantado, 'caminhar no labirinto" (NÓBREGA-THERRIEN; MENEZES; LUZ, 2018, p. 139), ou seja, os estudos foram selecionados com base na leitura prévia e na adequação de sua relevância e pertinência para com o exercício proposto. Isso se justifica pelo crescente uso generalizado dos termos "alfabetização" e "jogos digitais". Estes são empregados em diferentes contextos e campos do conhecimento, como alfabetização cartográfica, alfabetização cultural, alfabetização científica e tantos outros, dificultando a utilização de filtros e/ou operadores booleanos nos indexadores e bancos de dados de maneira eficiente.

Além disso, reconhecendo de antemão o aspecto multidisciplinar intrínseco à temática e buscando um panorama que contemple diferentes prismas observacionais do objeto de estudo, optamos por selecionar, neste artigo, publicações de diferentes áreas do conhecimento. O/A leitor/a deste artigo irá se deparar com estudos da área da linguística, ciências da computação, programação, educação e também obras elaboradas por equipes de natureza multidisciplinar, como o Núcleo de Política e Gestão Tecnológica da USP, que conta com pesquisadores da USP, da UFRJ, da PUC-SP, da UFBA, da UFPE; o Projeto ALADIM (Alfabetização e Letramento em Ambientes Digitais Multimodais) da UFMG, composto por professores e estudantes dos cursos de Belas Artes, Computação, Games, Letras e Pedagogia; ou ainda a Sociedade Brasileira 
de Computação, que reúne pesquisadores, estudantes, trabalhadores e empresários da área de jogos e entretenimento digital.

Para realizar o que propomos, recorremos aos jogos educativos digitais como ponto de encontro de diferentes áreas do saber que, através desse tipo de ferramenta didática, abordam e problematizam a alfabetização. A fim de possibilitar uma leitura mais fluida do texto, suprimimos da expressão "jogos educativos digitais de alfabetização" o termo "educativos", presumindo que o termo alfabetização em si já contempla o aspecto educativo. Dessa forma, convidamos o/a leitor/a deste trabalho a lembrar que nosso objeto de estudo é composto por materiais didáticos intencionais. Ou seja, excluem-se de nossa análise os jogos digitais que, como material didático não intencional, podem vir a ser utilizados no processo de alfabetização, porém não foram desenvolvidos exclusivamente para essa finalidade. Então, o que já se sabe sobre esses jogos digitais pensados para a alfabetização? Eis o que se apresenta a seguir.

A estrutura deste artigo está dividida em três seções, além da introdução e das considerações finais. $\mathrm{Na}$ seção dois a seguir, os jogos são problematizados dentro do cenário brasileiro, localizando especialmente a categoria dos jogos educacionais na indústria de jogos digitais. Na seção três, apresentamos parte dos textos selecionados no Estado da Questão (NÓBREGA-THERRIEN; THERRIEN, 2004; NÓBREGATHERRIEN; MENEZES; LUZ, 2018), realizados dentro do recorte temporal de algumas produções acadêmicas brasileiras que abordam a temática dos jogos digitais de alfabetização. São três textos: Karlini e Rigo (2014), Ribeiro (2012) e Basso et al. (2016). Na quarta seção, juntamos à discussão os demais textos do EQ: Cafiero e Coscarelli (2007), Coscarelli (2013), Yih An et al. (2013) e Ribeiro et al. (2015), que trazem interpolações sobre os jogos e os processos educativos.

\section{Problematizando os jogos}

Em 2014, o Grupo de Estudos e Desenvolvimento da Indústria de Games da Universidade de São Paulo - GEDIGames/USP, sob a coordenação do pesquisador Afonso Fleury, publicou um estudo detalhado denominado o Mapeamento da Indústria Brasileira e Global de Jogos Digitais. Foram constatadas modificações significativas no mercado de jogos digitais, pois os smartphones abriram novas possibilidades de uso dos jogos digitais permitindo a incorporação de milhões de jogadores de diferentes perfis etários e sociais (FLEURY et al., 2014). Com um olhar voltado ao mercado financeiro, o estudo de Fleury et al. (2015, p. 79) destaca as potencialidades dos Jogos Digitais Educacionais (JDE) ${ }^{1}$ no cenário, afirmando que:

Para os jogos de educação, os recursos financeiros necessários são relativamente pequenos. Esses jogos exigem equipes de desenvolvimento muito menores que as necessárias para desenvolver um jogo de console. A característica principal é que essas equipes têm um forte componente multidisciplinar, contando com o papel do designer instrucional, que deve fazer a mediação entre os conteúdos relativos à educação e a dinâmica do jogo.

Embora possa parecer uma publicação voltada para investidores, uma análise crítica da dinâmica do mercado de jogos pode nos mostrar mais do que potenciais de

${ }^{1} \mathrm{O}$ estudo citado utiliza o termo Jogos Digitais Educacionais com a sigla JDE. Em consideração aos autores da obra, mantivemos de pronto a nomenclatura na qualidade de citação. 
rentabilidade e retorno financeiro. $\mathrm{O}$ excerto acima evidencia como característica principal dos JDE a multidisciplinaridade na equipe de desenvolvimento, corroborando a visão apresentada neste nosso estudo. O mapeamento de Fleury et al. (2015) afirma que a presença de grandes desenvolvedores no cenário dos JDE ainda é pequena e controversa. Enquanto alguns analistas apostam no interesse crescente dessas corporações pelo segmento educacional, outros acreditam que não há entusiasmo dos grandes desenvolvedores de games por esse segmento. $\mathrm{O}$ estudo do grupo destaca também o importante papel das universidades no desenvolvimento de JDE (FLEURY et al., 2014). O documento questiona a qualidade dos jogos educacionais disponíveis na internet, afirmando que "na maioria dos portais há a distribuição gratuita, e estes sites apresentam os conhecidos JDE de "baixo orçamento, baixa qualidade" (FLEURY et al., 2014, p. 89).

Outro aspecto importante levantado pelo mapeamento é a falta de clareza quanto à definição do caráter pedagógico envolvido nos JDE:

Com relação aos aplicativos móveis, há aplicativos para a educação que não têm dinâmica de jogo de um JDE. Entretanto, muitos desenvolvedores e publicadoras classificam jogos infantis como JDE, mesmo que eles não tenham nenhum propósito educacional específico, além do entretenimento. [...] Entretanto, muitos jogos infantis de entretenimento são listados como educacionais, principalmente os encontrados para iOS, como Baby Pet Vet Doctor (George CL) e Toca Hair Salon 2 (Toca Boca AB). Esses aplicativos, por exemplo, são respectivamente simulações de clínica veterinária e salão de beleza, mas não têm objetivos educacionais claros. (FLEURY et al., 2014, p. 88).

Se por um lado há dificuldade em enxergar o componente pedagógico interiorizado nos jogos, por outro lado há também certa confusão quanto à definição daquilo que pode ser considerado jogo. No Brasil, os aplicativos educacionais com o maior número de downloads para smartphones nas plataformas Android e iOS são aplicativos de aprendizado de línguas estrangeiras, como o Duolingo e o Babbel: Learn Languages (Free Duolingo) e Learn English with babbel.com (babbel.com), os quais possuem objetivos educacionais explícitos. Porém, aplicativos como Turma da Galinha Pintadinha e Patati Patatá também são listados como educacionais e, da mesma forma, estão entre os principais downloads gratuitos para os dois sistemas operacionais de smartphones, apesar de terem propósito apenas de entretenimento, conforme os estudos realizados. Fleury et al. (2014, p. 89) salientam que "é importante destacar que poucos destes aplicativos disponíveis podem ser caracterizados como jogos".

Sobre esse mapeamento realizado pelo GEDIGames da USP, cabe ainda destacar que o segmento de jogos digitais destinados à inclusão social e ao empoderamento (Games for change) não foi investigado. O próprio documento reconhece a importância desses jogos por "suas externalidades e benefícios sociais" (FLEURY et al., 2014, p. 70). Contudo, justifica a ausência do segmento na abordagem pela "baixa rentabilidade desse tipo de jogo" (FLEURY et al., 2014, p. 70) e pelo fato de se tratar de um "setor de mercado pequeno para ser analisado de forma isolada, sendo bastante dependente de políticas públicas, pesquisas e doações institucionais (FLEURY et al., 2014, p. 70-71).

Do mesmo modo que a indústria de desenvolvimento de jogos digitais constata a conveniência de uma abordagem multidisciplinar na elaboração de jogos educativos, igualmente as produções acadêmicas e os/as pesquisadores/as da temática são sensíveis 
a essa inevitabilidade. Os estudos apresentados a seguir demonstram e exemplificam a preocupação e os esforços realizados no sentido de unir diferentes campos do saber no desenvolvimento de jogos digitais voltados para a alfabetização.

Após a problematização dos jogos digitais no contexto brasileiro, na seção a seguir, será analisado o primeiro grupo de estudos selecionado no EQ.

\section{As produções acadêmicas brasileiras sobre jogos digitais de alfabetização}

Aqui apresentamos o primeiro grupo de textos selecionados a partir do EQ que abordam a temática dos jogos digitais de alfabetização: Karlini e Rigo (2014), Ribeiro (2012) e Basso et al. (2016). Coincidentemente ao estudo de Fleury et al. (2014), também no ano de 2014, Diênifer Karlini e Sandro Rigo, pesquisadores da Universidade do Vale do Rio dos Sinos - UNISINOS, no Rio Grande do Sul, publicaram um artigo relatando um trabalho desenvolvido junto ao projeto Alfabetização e Letramento em Ambientes Digitais Multimodais - ALADIM, cujo objetivo principal é o desenvolvimento de jogos de plataformas voltados para a alfabetização (KARLINI; RIGO, 2014, p. 1149). No decorrer da elaboração de um protótipo de jogo digital, os autores declaram que sentiram "grande necessidade de apoio de diversas áreas relacionadas, tais como pedagogia, jogos, design e psicologia (KARLINI; RIGO, 2014, p. 1152). Tal necessidade fica evidenciada ao longo do relato dos pesquisadores.

O protótipo desenvolvido foi nomeado de ABClingo e "é composto por atividades de alfabetização, atendendo principalmente os níveis iniciais devido ao grau de dificuldade do mesmo" (KARLINI; RIGO, 2014, p. 1150). Nota-se que o públicoalvo é definido pelo grau de dificuldade e não pela metodologia pedagógica empregada na construção do jogo. Mas Karlini e Rigo (2014) chamam a atenção para o fato de que um jogo destinado aos níveis iniciais da alfabetização exige como primeiro passo do usuário que ele digite seu nome, o que é um contrassenso, pois talvez esse usuário, nesse nível, ainda não saiba digitar seu nome, apesar de ser uma das primeiras palavras ensinadas às crianças.

É preciso argumentar que o trabalho citado teve como objetivo "fornecer subsídios para métodos de Mineração de Dados Educacionais permitindo aos professores a observação de aspectos relevantes do processo dos alunos e a visualização de tendências e perfis" (KARLINI; RIGO, 2014, p. 1150). Portanto, o texto aborda e exemplifica como os dados, erros e acertos dos usuários são coletados/minerados, ${ }^{2}$ mas não especifica ou problematiza quais dados são pertinentes a serem considerados no processo de alfabetização, tampouco discute concepções de alfabetização empregadas no protótipo do jogo. Apesar disso, faz uma constatação bastante relevante quando identifica que:

A diversidade de jogos educacionais on-line, em sua maioria, não oferece recursos aos professores para que estes acompanhem individual e coletivamente os alunos de sua classe. Normalmente os professores não têm acesso aos acontecimentos ocorridos enquanto o aluno está jogando. (KARLINI; RIGO, 2014. p. 1150).

\footnotetext{
${ }^{2}$ Mineração de dados, ou utilizando o termo em inglês, data mining, conforme Camilo e Silva (2009), é uma ferramenta de apoio com papel fundamental na gestão da informação dentro das organizações. Seu uso permite descobrir padrões implícitos, tendências e relacionamentos entre dados, gerando assim novos dados e informações. Apesar de seu uso crescente em diversas áreas, sua aplicação na educação ainda é tímida, porém promissora.
} 
Assim, Diênifer Karlini e Sandro Rigo (2014) defendem que possibilitar ao/à professor/a o acesso a um registro dos caminhos percorridos pelos/as estudantes durante um jogo educativo, assim como erros, acertos e escolhas feitas por eles/as, se torna extremamente importante para o processo de ensino e aprendizagem, pois permite identificar as dificuldades dos/as discentes. Porém, conforme relatado no estudo, a maioria dos jogos educativos priva os professores dessas informações (KARLINI; RIGO, 2014, p. 1152). Ao que parece, os jogos digitais de alfabetização omitem informações valiosas - senão fundamentais - para uma ação docente exitosa.

Nesse sentido, Andréa Lourdes Ribeiro, pesquisadora da Universidade Federal de Minas Gerais - UFMG, publica, em 2012, um artigo analisando a contribuição dos jogos digitais para a aquisição da escrita. A doutora em estudos linguísticos afirma que "a inserção dos jogos na prática pedagógica requer do professor o exato conhecimento de como aquele jogo pode contribuir para o conhecimento buscado" (RIBEIRO, 2012, p. 112). Apenas apresentar o jogo ao estudante não é suficiente, “[...] é preciso que o professor defina objetivos pedagógicos e saiba o que e de que forma as crianças podem aprender com aquele jogo" (RIBEIRO, 2012, p. 112).

Observando estudantes da rede municipal de Belo Horizonte, com idade entre 6 e 7 anos, em diferentes fases de alfabetização, Ribeiro (2012) buscou identificar a forma como jogam e que hipóteses e conhecimentos elaboraram no momento do jogo. Conforme a autora, o jogo Brincando com as vogais, de acesso gratuito, foi o escolhido para a observação pelo fato de "[...] mobilizar atividades específicas e pertinentes ao processo de conhecimento da escrita e ser bastante rico no uso de imagens, cores, sons e movimentos destinados ao público infantil" (RIBEIRO, 2012, p. 111). Entender como as crianças jogaram provoca algumas reflexões, pois alguns dos estudantes observados "[...] não foram capazes de estabelecer a sonorização da vogal na palavra e a sua representação gráfica, devido ao pouco conhecimento sobre o sistema de escrita, [e] optaram por jogar na base da tentativa" (RIBEIRO, 2012, p. 111). Isso significa que os acertos não necessariamente significam aprendizagem, já que “[...] repetiram os erros e mudaram os acertos nas tentativas seguintes" (RIBEIRO, 2012, p. 111).

Ao iniciar a segunda fase, o jogo apresenta na tela um texto contendo as instruções e os comandos necessários para a realização da atividade. A autora relata que os estudantes tentaram ler a instrução, mas não conseguiram, "[...] pois o tempo de apresentação da tela não foi suficiente para a leitura mais vagarosa, sílaba a sílaba". (RIBEIRO, 2012, p. 119-120). Nesse aspecto, o jogo demonstra um certo descuido por parte da equipe desenvolvedora. Coube à pesquisadora fazer uma ressalva à ferramenta educativa sugerindo aos elaboradores "[...] aplicar os recursos sonoros também nas instruções" (RIBEIRO, 2012, p. 125). A pesquisadora observa também que, apesar de se divertirem, "as crianças logo se cansaram do jogo [...] muitas dominaram o jogo rapidamente, $[. .$.$] as que foram bem sucedidas se sentiram inicialmente motivadas a$ colocar em ação seus conhecimentos sobre a escrita para vencer, mas logo 'desistiram' por não haver mais desafio para elas no jogo" (RIBEIRO, 2012, p. 120).

Confrontando os estudos de Ribeiro (2012) e de Karlini e Rigo (2014), caso o jogo analisado por Ribeiro (2012) dispusesse dos mecanismos de mineração de dados postulados e desenvolvidos no estudo de Karlini e Rigo (2014), possivelmente Ribeiro (2012) teria mais dados e dados mais precisos para sua análise. É justo ressaltar que o estudo de Karlini (2014) é posterior ao estudo de Ribeiro (2012).

Vejamos agora um estudo de 2016 elaborado por acadêmicos do curso de Bacharelado em Sistemas de Informação do Departamento de Tecnologia da Informação da Universidade Federal de Santa Maria - UFSM, também no Rio Grande 
do Sul. Assim como as demais obras aqui apresentadas, o artigo de Maik Basso e colaboradores (2016) pode nos situar a maneira como as áreas da ciência da computação têm enxergado e colaborado com o campo da alfabetização.

Maik Basso e colaboradores (2016, p. 21) se propuseram a desenvolver, na área de alfabetização, "um protótipo de jogo educacional [...] voltado para crianças de cinco a sete anos de idade [...] com o intuito de apoiar os processos de ensino e de aprendizagem da escrita". O jogo recebeu o nome Aprendendo com Zag. No desenvolvimento do protótipo, os pesquisadores empregaram técnicas de Inteligência Artificial (IA), "por meio de Redes Neurais Artificiais (RNA)" (BASSO et al., 2016, p. 21). Nota-se uma simplicidade inconveniente dos autores ao tomarem como referencial teórico sobre a alfabetização apenas dois autores, sendo um trabalho de conclusão de curso de licenciatura em Pedagogia e o outro um artigo elaborado para a disciplina de Fundamentos e Métodos da Alfabetização do $5^{\circ}$ semestre do curso de Pedagogia. Nesse sentido, fica questionada a ausência de uma conceituação sólida da temática principal do jogo, já que há diversos/as autores/as consagrados/as com décadas de pesquisas sobre o tema. Esse vácuo conceitual é nítido nas considerações finais do grupo quando, ao reconhecerem a necessidade de um trabalho interdisciplinar no desenvolvimento do projeto, omitem os conhecimentos pedagógicos nele utilizados:

A maior dificuldade encontrada no desenvolvimento deste projeto envolveu a interdisciplinaridade e o grande número de tecnologias/ferramentas utilizadas, pois, para a construção de um jogo, faz-se necessário integrar diferentes áreas do conhecimento. Neste jogo foram utilizados conhecimentos sobre projeto de jogos, produção sonora, produção visual, sem contar o estudo sobre as tecnologias de desenvolvimento de jogos e de aplicação dos algoritmos de RNA. (BASSO et al., 2016, p. 35).

Detalhando o jogo, a IA é utilizada em Aprendendo com Zag para reconhecer as letras desenhadas pelo jogador com o uso do mouse. Basso et al. (2016) descrevem o processo de reconhecimento das letras pelo programa destacando o papel das redes neurais artificiais, o treinamento dessas redes, as matrizes pixeladas definidas para esse treinamento, bem como os programas auxiliares utilizados no desenvolvimento do protótipo. É possível supor que o foco dos pesquisadores estava em exemplificar as possibilidades de aplicação da IA em jogos educativos. Porém, negligenciando ou relegando a alfabetização a um segundo plano, acabam expostos a críticas de olhares atentos aos princípios pedagógicos. Apesar de elucidarem com domínio as técnicas de programação que empreenderam no desenvolvimento do protótipo, ao proporem um jogo no qual "[...] os alunos se sentirão mais motivados em aprender, não ficando limitados ao uso de papel e lápis" (BASSO et al., 2016), esperamos que tal ferramenta não transponha a mesma limitação para a tela do computador. Apesar disso, ao descreverem a implementação do jogo, os pesquisadores se colocam em uma posição contraditória, pois a proposta do jogo acaba por repetir no computador a mesma atividade desenvolvida com lápis e papel:

O segundo nível do jogo dispõe de um quadro contendo uma letra em vermelho e o jogador deve escrever sobre a mesma para que possa memorizar como se escreve a letra. [...]

Por fim, tem-se o terceiro e último nível do jogo, que também é o mais importante porque é o foco deste trabalho. Este nível segue a mesma lógica do nível anterior, porém possui algumas particularidades. Nesta 
fase, a professora de Zag diz uma letra ao jogador, que deve escrevê-la no quadro em branco, sem auxílio de nenhuma imagem, e clicar no botão verde para verificar a sua resposta. (BASSO et al., 2016, p. 32).

Cabe questionar: até que ponto é válido a criança aprender a desenhar as letras no computador, repetindo uma atividade que é feita no papel? Seria essa a melhor forma de utilizar essa ferramenta? Quem aprendeu mais nesse processo: os jogadores ou a inteligência artificial? Mesmo com o deslize, o estudo dos acadêmicos da UFSM traz uma constatação preciosa para nossa análise em questão. Afirmam que a "[...] utilização de técnicas de IA no desenvolvimento de jogos digitais está se tornando cada vez mais comum, devido ao aumento da complexidade dos jogos e de seus recursos cada vez mais bem elaborados e realistas" (BASSO et al., 2016, p. 24). Isso implica novamente discutir como se dá a incorporação dessas técnicas de desenvolvimento de jogos nos processos cognitivos relacionados à alfabetização e vice-versa. Para isso, precisamos chamar à roda outros saberes - da linguística, da psicologia, da ciência da computação, da pedagogia, entre outros - como faremos adiante na análise da relação entre os jogos e os processos educativos, buscando problematizar se as teorias de aprendizagem são aplicadas ou não na elaboração desses jogos.

\section{Análise da relação entre os jogos e os processos educativos}

Nesta seção, juntamos à discussão os demais textos do EQ: Cafiero e Coscarelli (2007), Coscarelli (2013), Yih An et al. (2013) e Ribeiro et al. (2015); que trazem interpolações sobre os jogos e os processos educativos.

Em 2013, um grupo de pesquisadores do Instituto Federal do Espírito Santo publicou um artigo descrevendo o jogo Digita, desenvolvido com "o intuito de apoiar a alfabetização de crianças" (YIH AN et al., 2013, p. 154). Esse jogo educativo de apoio ao processo de alfabetização infantil se propõe a ir "[...] além de métodos de alfabetização que envolvam mais do que a repetição mecânica de exercícios" (YIH AN et al., 2013, p. 154). Pertinentemente, o estudo afirma que as pesquisas realizadas no final da década de 1990 evidenciam que "[...] muitos dos softwares existentes não enfatizavam a importância de um contexto para a alfabetização, buscando apenas exercitar a escrita e leitura da palavra" (YIH AN et al., 2013, p. 154). E apresentam outra constatação pertinente à nossa leitura, afirmando que, "[...] em uma análise mais geral sobre os principais softwares da atualidade, percebe-se que também são carentes de atividades que envolvam mais do que o treino de habilidades" (YIH AN et al., 2013, p. 154). E compartilhando das considerações do estudo de Ribeiro (2012), citado anteriormente, Yih An et al. (2013, p. 155) afirmam que nos jogos "[...] faltam desafios à criança". Trazendo um referencial teórico mais robusto, descrevem e posicionam as bases metodológicas que são aplicadas ao jogo desenvolvido e reconhecem que, além dos requisitos de qualidade comuns a outros programas computacionais, "[...] os jogos educativos precisam ter atributos pedagógicos, voltados para o aprendizado efetivo do seu público-alvo" (YIH AN et al., 2013, p. 157). Entretanto, igualmente ao jogo Aprendendo com Zag, exigem na primeira tela apresentada o cadastro do usuário, o que não cabe num jogo pensado para crianças em processo de alfabetização. Mas Yih An et al. (2013, p. 158) fazem uma ressalva importante: "No login, a criança deve se cadastrar, sendo aconselhado o apoio de um adulto para essa etapa inicial". Essa dificuldade inicial contrasta com a proposta adotada no decorrer do jogo. Ao definirem como público-alvo crianças em processo de alfabetização, buscaram “[...] permitir que a 
criança use a imaginação para resolver o problema" (YIH AN et al., 2013, p. 160). Nesse sentido, alegam que "[...] os cenários do jogo, em sua maioria, contêm situações cotidianas e problemas simples de resolver" (YIH AN et al., 2013, p. 160).

Parecendo prever os apontamentos colocados no estudo posterior de Karlini e Rigo (2014), citados anteriormente, Yih An e colaboradores (2013, p. 162) apontam para a necessidade de "disponibilizar relatórios que permitam uma melhor análise dos educadores sobre seus alunos, especialmente sobre onde se concentram os erros e dificuldades", bem como "estabelecer procedimentos metodológicos para coleta e análise dos dados" (YIH AN et al., 2013, p. 162).

Os estudos citados até aqui exemplificam a dificuldade encontrada por estudantes, professores, pesquisadores e desenvolvedores de jogos em conciliar diferentes áreas do conhecimento em um jogo digital de alfabetização. Essa situação condiz com os apontamentos do estudo Teorias de Aprendizagem em Jogos Digitais Educacionais: um panorama brasileiro, o qual buscou "[...] identificar as teorias de aprendizagem aplicadas em jogos digitais educacionais desenvolvidos no Brasil, voltados ao ensino básico, no período de 2004 a 2014” (RIBEIRO et al., 2015, p. 2). Os pesquisadores observaram que, apesar do crescente uso do jogo como parte integrante do ensino-aprendizagem, a elaboração, o desenvolvimento e a aplicação dos jogos acontecem de forma desvinculada das teorias de aprendizagem em boa parte dos casos. A pesquisa de Ribeiro et al. $(2015$, p. 8$)$ revela ainda um dado que nos preocupa sobre as teorias envolvidas nos processos educativos:

[...] os jogos digitais educacionais divulgados em pesquisas brasileiras não contemplam, em 40,74\% dos casos, uma preocupação com o emprego de teorias de aprendizagem. A análise também mostra uma baixa diversidade de teorias de aprendizagem aplicadas em jogos brasileiros, sendo a teoria de Piaget e a de Vygotsky as mais utilizadas. Considerando a amostra brasileira analisada, a escolha de concepções pedagógicas para a fundamentação de jogos digitais condiz com o estado de arte internacional, ou seja, há uma preferência por teorias de aprendizagem de base construtivista.

Os autores argumentam que a ausência de teorias de aprendizagem em 40,74\% dos jogos não colabora para a consolidação do emprego da aprendizagem baseada em jogos digitais em ambientes de ensino, pois os "jogos desenvolvidos sem uma concepção pedagógica de referência podem produzir resultados distintos dos concebidos" (RIBEIRO et al., 2015, p. 7). Logo, convém refletirmos se alguns dos jogos digitais de alfabetização não estão produzindo um efeito contrário ao esperado. É inquietante confrontar a proposta de alguns jogos digitais de alfabetização com os pressupostos de Foucambert (1994, p. 13), que, no livro A leitura em questão, definiu doze maneiras de tornar difícil a aprendizagem da leitura:

1. Estabeleça como meta o domínio precoce das regras de leitura.

2. Cuide bem para que a fonética seja aprendida e utilizada.

3. Ensine as letras ou as palavras, uma a uma, certificando-se de que cada letra ou palavra foi assimilada antes de passar para a seguinte.

4. Defina como objetivo principal uma leitura palavra por palavra perfeita.

5. Não deixe as crianças adivinharem; pelo contrário, exija que elas leiam com atenção.

6. Procure evitar de todas as maneiras que as crianças errem.

7. Dê um feedback imediato. 
8. Detecte e corrija os movimentos incorretos dos olhos.

9. Identifique eventuais disléxicos e trate-os o mais cedo possível.

10. Esforce-se para que as crianças aprendam a importância da leitura e a gravidade do fracasso.

11. Aproveite as aulas de leitura para melhorar a ortografia e a expressão escrita; insista também em que os alunos falem a melhor língua possível.

12. Se o método utilizado não lhe satisfizer, tente outro. Esteja sempre alerta para achar material novo e técnicas novas.

Se Foucambert (1994) estiver correto (e pensamos que sim na maioria das afirmações) e sendo essas práticas algo que devemos minimizar, não deveríamos encontrar nelas as ações promovidas por alguns jogos digitais de alfabetização. Pelo contrário. Por isso, nesse sentido, refazemos o questionamento: os jogos digitais de alfabetização, desenvolvidos sem a devida preocupação pedagógica, facilitam ou tornam mais complicada a alfabetização?

Apenas fazer críticas é relativamente fácil e bastante simplista. O complexo é analisar as falhas, contradições e problemáticas para procurar soluções. Essas são sempre provisórias, passadas sua temporalidade e seu arco geográfico, voltam a se configurar em falhas, contradições e novas problemáticas. De qualquer forma, é importante destacar os estudos que demonstram comprometimento em contribuir de forma responsável com a temática - e com base teórica.

Um desses estudos fala justamente das dificuldades e dos desafios de construir uma matriz de referência para o desenvolvimento de jogos de alfabetização. Trata-se de uma publicação de 2007, das autoras Delaine Cafiero e Carla Coscarelli. Sob o título Competências e habilidades na alfabetização: como construir uma matriz de desempenho para um jogo, o artigo afirma que uma matriz prevê um conjunto de saberes necessários para considerar um sujeito capaz de resolver determinados problemas. No caso da alfabetização, "uma matriz precisa prever que conhecimentos os aprendizes devem possuir e que ações devem realizar na leitura da escrita" (CAFIERO; COSCARELLI, 2007, p. 92). Mas, apesar de tentar prever os conhecimentos e ações necessários aos processos educativos em alfabetização, Cafiero e Coscarelli (2007, p. 92) afirmam que “[...] não há como prever todas, mas é possível destacar uma boa parte das ações necessárias ao processo do alfabetizando". Para as autoras, na elaboração de uma matriz para um jogo de alfabetização, basicamente três desafios se impõem: “[...] o primeiro seria inventariar as habilidades e competências que a interação com o jogo teria que mobilizar" (CAFIERO; COSCARELLI, 2007, p. 92), com a implicação de que "[...] a tarefa de inventariar habilidades de leitura e escrita a serem desenvolvidas na interação com o jogo tem de, necessariamente, ir além da mera mecanização de regras fonológicas, morfológicas, sintáticas" (CAFIERO; COSCARELLI, 2007, p. 92); o segundo desafio, após levantadas as habilidades e competências que o jogo precisa desenvolver, é o de considerar a "[...] apropriação do sistema da língua e [a] inserção do sujeito nas práticas sociais de uso da leitura e da escrita" (CAFIERO; COSCARELLI, 2007, p. 93-94); o terceiro desafio apontado pelas autoras é o de "buscar hierarquizar descritores de habilidades e competências de modo a permitir sua implementação" (CAFIERO; COSCARELLI, 2007, p. 95). Reconhecendo a dificuldade imposta na tarefa, as autoras ponderam que:

[...] não havendo uniformidade na aprendizagem, como hierarquizar o que não é hierarquizável? A cognição é reticular e dinâmica, não há um só caminho na construção de um conhecimento. Cada indivíduo 
pode criar atalhos específicos dependendo de suas experiências com o mundo, dependendo dos outros conhecimentos que já construiu. Então, como traçar uma rota que ele possa seguir? (CAFIERO; COSCARELLI, 2007, p. 95).

Sem definir uma resposta aos seus questionamentos, Cafiero e Coscarelli (2007, p. 95) sugerem que "[...] o jogo a ser construído deve lidar com a autonomia do sujeito e respeitar sua própria natureza, não pode ter apenas uma via de acesso". Ou seja, o jogo deve permitir ao alfabetizando "várias portas de entradas para o jogo" (CAFIERO; COSCARELLI, 2007, p. 95), possibilitando ao estudante decidir por ele mesmo a trilha a ser seguida. Nesse sentido, acreditam que o jogo deve ter "atividades que comecem pelas unidades menores (identificação de fonemas, de letras, por exemplo), mas ao mesmo tempo deverá ter outras portas que se abrem por meio de identificação de palavras, de audição e de identificação de textos" (CAFIERO; COSCARELLI, 2007, p. 95). Em outras palavras, as autoras defendem que é o jogo que deve se adaptar ao estudante, e não o contrário.

Coscarelli (2013) volta a discutir o assunto em outro artigo publicado seis anos depois. O estudo apresenta uma síntese das atividades e resultados de pesquisas realizadas pelo projeto Alfabetização e Letramento em Ambientes Digitais Multimodais da UFMG. A análise produzida pela autora é tão pertinente para nós que, apesar de extensa, optamos por transcrever o trecho completo no qual ela apresenta a análise de jogos de alfabetização disponíveis na internet:

Analisando vários aspectos desses jogos, a saber: interface e instruções, feedback, concepção de aprendizagem, contextualização, repertório linguístico, recursos, tarefas, recompensa, desafio, funcionamento do jogo, pudemos observar que os jogos não atendem bem a vários desses quesitos.

Os jogos deixam a desejar porque a concepção de aprendizagem da maioria desses jogos é behaviorista, ou seja, há uma indicação para o jogador de que ele acertou ou errou, mas não há feedback suficiente para que ele compreenda o seu erro, nem que sirva de orientação para que ele seja capaz de acertar numa outra jogada.

Nem sempre é fácil identificar os conteúdos e as habilidades trabalhados nos jogos, e normalmente as atividades lidam com letras, sílabas ou palavras, raramente lidando com parágrafos, textos, suportes ou situações contextualizadas de leitura e escrita. Os jogos costumam ser apenas uma transposição de atividades que podem ser encontradas ou feitas no impresso para a tela do computador, e não exploram os recursos tecnológicos disponíveis atualmente.

As tarefas são normalmente repetitivas e o repertório linguístico (letras, sílabas ou palavras) explorado nos jogos é reduzido, não havendo, na maioria das vezes, uma organização clara dos conteúdos por grau de dificuldade ou algum outro critério que revele as concepções linguísticas que motivaram as escolhas do repertório ou sequência.

Nesses jogos, os jogadores não recebem recompensas, prêmios, vidas, assim como também não correm riscos, não perdem vidas, entre outros desafios e motivações que atraem e motivam os jogadores. (COSCARELLI, 2013, p. 6).

A análise de Coscarelli (2013) corrobora em vários pontos o que foi exposto até aqui, como a questão de poucas opções de sites pensados para os processos 
educativos de alfabetização. Além do número reduzido de materiais on-line, entre os existentes, a autora destaca a base teórica e pedagógica comportamentalista subjacente, contrariando o trazido por Ribeiro et al. (2015) de que os teóricos mais utilizados seriam Piaget e Vygotsky, ou seja, nomeados como construtivistas. Outro ponto importante trazido por Coscarelli (2013) é a baixa frequência de textos, descontextualizando a leitura da palavra. Além disso, apenas transpor o que seria possível com lápis e papel para uma tela não nos parece o melhor uso dos recursos digitais, crítica também feita a Basso et al. (2016) neste artigo. Outro fator importante a ser considerado no desenvolvimento de jogos digitais de alfabetização é a motivação: o jogador precisa ser desafiado, como ocorre em jogos para entretenimento.

Ainda em suas considerações finais, a autora insiste na interdisciplinaridade, sobre a qual mencionamos no início do texto e ao longo desta seção. Concordamos com a autora quando afirma que existe muita tecnologia disponível que pode e deveria ser utilizada na aprendizagem, porém isso não é tarefa de apenas um programador de jogos, ou de um especialista em Educação ou Letras, mas sim de uma equipe multidisciplinar que discuta as bases teóricas da criação desses jogos com fins educacionais.

\section{Considerações finais}

Os estudos sobre jogos analisados neste artigo demonstram a necessidade de uma ação necessariamente conjunta e interdisciplinar (FAZENDA, 2008) na produção, no desenvolvimento e na aplicação desse tipo de ferramenta, em especial no campo dos processos educativos da alfabetização - área, por excelência, interdisciplinar. Em alguns casos, as produções acadêmicas analisadas, embora apresentem avanços significativos, ainda carecem de maior debate, problematização e embasamento sobre as teorias pedagógicas e os processos de ensino envolvidos nos jogos digitais de alfabetização.

Apesar de ser um recorte reduzido quanto ao número de estudos analisados, este artigo procurou ser o mais democrático possível quanto às áreas de conhecimento contempladas na discussão acerca do objeto de estudo. Procuramos amostras de diferentes áreas que nos permitissem vislumbrar - em nosso horizonte pedagógico indícios das abordagens por elas adotadas e, desse modo, acreditamos que foi possível encontrar pontos positivos e pontos que carecem de melhorias, desenvolvimento e amadurecimento. Realizamos o EQ (NÓBREGA-THERRIEN; THERRIEN, 2004; NÓBREGA-THERRIEN; MENEZES; LUZ, 2018) de forma intuitiva, reflexiva e criteriosa, indo além dos limites do levantamento bibliográfico; permitindo um posicionamento que condiz com nossa concepção de alfabetização dentro deste labiríntico percurso epistemológico de um mestrado acadêmico em Educação em um Instituto Federal.

Aliado a isso, em nossa sociedade contemporânea, na qual a participação democrática vem cada vez mais se apoiando, sendo transferida e até mesmo se efetivando em ambientes virtuais, nas redes sociais e outros mecanismos de comunicação on-line, o acesso e o bom uso dos recursos tecnológicos e dispositivos eletrônicos - em conjunto com a leitura e a escrita fluentes - são condições sine qua non que se fazem fundamentais para a emancipação do indivíduo como cidadão no sentido pleno da palavra. Dito isso, podemos considerar os jogos digitais de alfabetização como importantes catalisadores educacionais, com vistas a uma prática pedagógica libertadora (FREIRE, 1996), que vislumbre a formação de cidadãos críticos e a promoção da autonomia intelectual, pois, além de participar dos processos 
educativos da leitura e escrita, coloca o estudante em contato com as tecnologias digitais, tão necessárias para a participação democrática.

\section{Referências}

BASSO, Maik; KLISZCZ, Silvana; PARREIRA, Fábio J.; SILVEIRA, Renato S. Jogo educacional digital para auxílio à alfabetização utilizando redes neurais. Revista EducaOnline. Rio de Janeiro, v. 10, n. 2, p. 20-37, maio/ago. 2016.

CAFIERO, Delaine; COSCARELLI, Carla. Competências e habilidades na alfabetização: como construir uma matriz de desempenho para um jogo? Revista Língua Escrita. Belo Horizonte, n. 2, p. 88-96, dezembro. 2007. Disponível em: http://www.ceale.fae.ufmg.br/app/webroot/files/uploads/revista $\% 20$ lingua $\% 20$ escrita/Li nguaEscrita_2.pdf. Acesso em: 18 out. 2019.

CAMILO, Cássio Oliveira; SILVA, João Carlos da. Mineração de dados: conceitos, tarefas, métodos e ferramentas. In: RELATÓRIO TÉCNICO DO INSTITUTO DE INFORMÁTICA DA UNIVERSIDADE FEDERAL DE GOIÁS, ago. 2009.

COSCARELLI, Carla. Projeto ALADIM: jogos digitais e novas interfaces para alfabetização. Revista Triângulo. Uberaba, v. 6, n. 2, p. 4-15.

FAZENDA, Ivani (org.). O que é interdisciplinaridade? São Paulo: Cortez, 2008.

FREIRE, Paulo. Pedagogia da autonomia. São Paulo: Paz e Terra, 1996.

FLEURY, Afonso; NAKANO, Davi; CORDEIRO, José Henrique Dell Osso (coord.). Mapeamento da Indústria Brasileira de Jogos Digitais. São Paulo: NPGT / Escola Politécnica / USP, 2014.

FOUCAMBERT, Jean. A leitura em questão. Porto Alegre: Artes Médicas, 1994.

GUEDES, Paulo Coimbra; SOUZA, Jane Mari de. Leitura e escrita são tarefas da escola e não só do professor de português. In: NEVES, Iara Conceição Bitencourt (org.) Ler e escrever: compromisso de todas as áreas. 9. ed. Porto Alegre: Editora UFRGS, 2011. p. 19-24.

KARLINI, Diênifer; RIGO, José Sandro. ABCLINGO: integrando jogos sérios e mineração de dados educacionais no apoio ao letramento. In: XIII SBGAMES, 2014, Porto Alegre, Anais [...]. p. 1149-1152.

NÓBREGA-THERRIEN, Sílvia Maria; THERRIEN, Jacques. Trabalhos científicos e o Estado da Questão: reflexões teórico-metodológicas. Estudos em Avaliação Educacional, v. 15, n. 30, jul./dez., 2004. Disponível em: http://publicacoes.fcc.org.br/ojs/index.php/eae/article/view/2148/2105. Acesso em: 30 maio 2020.

NÓBREGA-THERRIEN, Sílvia Maria; MENEZES, Eunice Andrade de Oliveira; LUZ, Carolina Nóbrega Sabóia. Estudos sobre pesquisa e reflexão na formação docente: o 
Estado da Questão. Revista de Educação, Ciência e Cultura - RECC, Canoas, v. 23, n. 2, p. 137-157, jul. 2018. Disponível em: https://revistas.unilasalle.edu.br/index.php/Educacao/article/view/4506/pdf. Acesso em: 31 maio 2020.

RIBEIRO, Andréa Lourdes. Aquisição da escrita na era virtual: incorporando os jogos digitais on-line. Domínios de Lingu@gem. Uberlândia, v. 6, n. 2, p. 111-127, 2012.

ROYES SCHARDOSIM, Chris; ALVES, Thiago Ribeiro. Alfabetização, literacia e letramento: diferentes conceitos de um caminho comum. LínguaTec, v. 4, p. 76-93, 2019.

ROYES SCHARDOSIM, Chris; FUSINATO, Suélen. Alfabetização: uma proposta interdisciplinar. Revista Querubim (On-line), v. 1, p. 97-103, 2017.

SOARES, Magda. Alfabetização no Brasil: o estado do conhecimento. Brasília: INEP/MEC, 1989.

YIH AN, Ding; SILVA, Cesar D. da; RIBEIRO, Danton M. G.; ROCHA, Perla B. R. da; MALTINTI, Caio; NUNES, Vanessa B.; FÁVERO, Rutinelli. Digita - um jogo educativo de apoio ao processo de alfabetização infantil. In: II CONGRESSO BRASILEIRO DE INFORMÁTICA NA EDUCAÇÃO, 2013, São Paulo, Anais [...], p. 154-163.

Recebido em 30 de novembro de 2019

Aceito em 31 de maio de 2020 